\title{
An analysis of E-waste flows in China
}

\author{
Albert Veenstra • Cathy Wang • \\ Wenji Fan · Yihong Ru
}

Received: 20 July 2009 / Accepted: 6 October 2009 / Published online: 20 October 2009

(C) The Author(s) 2009. This article is published with open access at Springerlink.com

\begin{abstract}
In Europe, legislation about waste of electrical and electronic equipment (WEEE) recovery and recycling has been introduced in 2002, and corresponding legislation in the EU Member States was in place in August 2005 (EU-EC 2003). In the same period, China has been developing WEEE regulation as well. The main contribution to date to the Chinese legislative framework is the 'Circular Economy Promotion Law of the People's Republic of China' that was approved on August 29, 2008, and came into force as of January 1, 2009. Both these legislative systems contain the Extended Producer Responsibility as a core concept, as well as a formal, and, in the case of China, centralised, recovery system. Given the conceptual similarities of legislation on WEEE, but striking differences in the product recovery systems in China and the EU, it is of interest to investigate if the existing recovery and recycling system in China actually fits the new legislation. Currently, there is anecdotal evidence that, in China, much of the WEEE flows into informal recycling channels such as secondhand market and manual recycling workshops. Not much is known otherwise because a formal governance system and official statistics collection do not exist yet. More particularly, the actual WEEE flow in China, or in particular cities, is virtually
\end{abstract}

\footnotetext{
A. Veenstra $(\varangle)$

Rotterdam School of Management, Erasmus University Rotterdam,

P.O. Box 1738, 3000 DR, Rotterdam, The Netherlands

e-mail: aveenstra@rsm.nl

C. Wang · W. Fan · Y. Ru

School of Economics and Management,

Beijing Jiaotong University,

Beijing, People's Republic of China
}

unknown, as is the relationship between collection, treatment, re-selling and disposal. This paper suggests a Markov chain model that allows for the analysis of the flow of WEEE through the reverse chain from point of collection through to final disposal. We analyse this system in its equilibrium state and investigate the impact of scenarios that reflect key elements of the new WEEE regulation in China. In addition, we offer a qualitative analysis of the various scenarios for the three dimensions of sustainability: people, planet and profit. This research offers specific suggestions to strengthen the Chinese WEEE recovery and recycling system that would bring the actual system more in line with the current policy.

Keywords WEEE - China - Markov chain • Product recovery $\cdot$ Secondhand market

\section{Introduction}

In Europe, legislation about waste of electrical and electronic equipment (WEEE) recovery and recycling has been introduced in 2002, and corresponding legislation in the EU Member States was in place in August 2005 [5]. The core of this legislation is the extended producer responsibility (EPR), where the original manufacturer assumes responsibility for product recovery and recycling. Recovery in Europe takes place in many different ways, but some of the key elements are replacing old for new products at retailers or dealers, and the immediate recycling of these recovered products. Reuse of secondhand products is not very common.

China has been developing environmental regulation, and in particular, WEEE regulation over the last 5 
Table 1 Forecasted scrapping volume of five major electronic equipment types $(\times 1000$ units $)$
Source: China's Plastics Statistics Yearbook 2006. Projections from 2006 onwards

\begin{tabular}{lccccrrr}
\hline Year & Refrigerator & $\begin{array}{l}\text { Air } \\
\text { conditioner }\end{array}$ & $\begin{array}{l}\text { Washing } \\
\text { machine }\end{array}$ & Television & Computer & Total & $\begin{array}{l}\text { Growth } \\
\text { rate }(\%)\end{array}$ \\
\hline 2001 & 6,708 & 630 & 10,942 & 14,358 & 246 & 32,884 & \\
2002 & 4,631 & 1,580 & 9,484 & 16,892 & 836 & 33,422 & 16 \\
2003 & 4,699 & 3,464 & 10,747 & 20,577 & 1,388 & 40,876 & 223 \\
2004 & 4,858 & 3,934 & 12,545 & 25,376 & 2,066 & 48,778 & 193 \\
2005 & 5,967 & 6,826 & 12,073 & 27,113 & 2,914 & 54,893 & 125 \\
2006 & 7,681 & 7,862 & 13,422 & 34,970 & 4,050 & 67,985 & 239 \\
2007 & 9,185 & 9,740 & 14,430 & 42,620 & 6,720 & 82,695 & 216 \\
2008 & 9,797 & 11,569 & 13,416 & 39,360 & 8,777 & 82,918 & 3 \\
2009 & 10,444 & 13,376 & 15,958 & 40,937 & 14,635 & 95,350 & 150 \\
2010 & 10,600 & 18,267 & 19,645 & 51,550 & 32,167 & 132,228 & 387 \\
2011 & 12,100 & 23,336 & 25,334 & 65,414 & 59,749 & 185,934 & 406 \\
2012 & 12,790 & 31,351 & 30,355 & 74,318 & 80,849 & 229,664 & 235 \\
\hline
\end{tabular}

to 10 years. Much of this legislation is based on existing environmental regulation in other parts of the world. The main contribution to date to the Chinese legislative framework is the 'Circular Economy Promotion Law of the People's Republic of China' that was approved on August 29, 2008, and came into force as of January 1, 2009. This law also contains the EPR as a core concept, as well as centralised (i.e. government-controlled) recovery and recycling systems.

In practice, in China, a large part of the WEEE flows into two channels. One is an informal ${ }^{1}$ collection channel where hawkers, peddlers and individual vendors repair, refurbish and then resell the WEEE. In the other, WEEE is recycled for components and raw material after being taken apart mostly in small handcraft workshops. These ways of disposal produce a high level of waste of valuable resources and pollution of the environment (see, for instance, [2]), but also results in problems for the buyers of the secondhand electronic products as a result of unsafe and inexpertly repaired products. There are also some official recycling facilities, often developed by governmental agencies, but a large part of this handful of facilities have great difficulty obtaining enough product to break even.

At this point in time, an investigation of the recovery and recycling system in China is urgently needed to see if the current product recovery system fits with the legislation that is conceptually similar to that in Europe. We suggest to use a Markov Chain model to obtain more insight in current WEEE flows. This model, essentially a mapping of the various paths from discarded product to waste, will reveal the relationships between the various stages the e-waste goes through before ending up as actual waste, and it will allow

\footnotetext{
${ }^{1}$ The term 'informal', as opposed to 'formal', refers to the almost complete absence of regulation or government supervision.
}

testing of policy scenarios. We also aim to assess the changes in the system due to these policy scenarios along the dimensions of sustainability: people, planet and profit. On the basis of the analysis presented here, we will formulate recommendations for the Chinese government to improve the current recovery and recycling system for WEEE.

The paper is organised as follows. We first review the current state of affairs in WEEE recycling and some existing literature on the WEEE system in China. We then introduce our modelling approach and data. The sections after that report on the analysis of the model and the scenarios and the sustainability assessment of the scenarios. The paper finishes with some concluding remarks and recommendations.

\section{Review of the Chinese WEEE system}

Currently, China is scrapping the largest number of home appliances since 2003. Theoretical scrapping volume predictions of five electrical appliances, televisions, refrigerators, washing machines, personal computers and air-conditioners, from 2001 to 2012 are presented in the Table 1. The table shows the scrapping volume increases on a year-on-year basis with an average annual growth rate of $19.9 \%$. In 2007 , the total scrapping volume is expected to reach 83 million units. Among the five categories, the scrapping volume of personal computers in China increases at the largest rate of $76.3 \%$, followed by air-conditioners at $48.1 \%$, TV sets at $16.7 \%$, washing machines at $10.5 \%$ and refrigerators at $7.2 \%$.

Faced with these rising numbers of electronic waste, China has yet to establish a regulated electrical and electronic equipment recycling and administration system. However, the tendency seems to be for China to adopt key concepts from the European approach, in 
which EPR is a central idea, as well as nationwide recovery systems, and immediate recycling after recovery. One key issue in the European situation is that products that are disposed of are considered waste that has no value. In China, waste is, in first instance, very valuable, and a large formal and informal waste processing economy exists that aims to capture any value that is present in what people and companies throw away.

At present, many of the contributions to WEEE research in China focus on the basic structure and state of the art of the current e-waste recycling system. See He et al. [7] for a review on the status of WEEE treatment in China. Much of the system mappings that are reported are still based on limited observations, and very few authors attempt some form of optimisation (but see $[19,25]$ and [20]). Streicher-Porte and Yang [17], Yang et al. [24] and Liu et al. [13] present partial attempts to map the WEEE collection and recycling system in Beijing. Cao and $\mathrm{Xu}$ [3] indicate that the key issues for developing models and solutions for the recycling of WEEE in China are the complexity and uncertainty of the collection and recycling process. Information on formal recycling capacity is not widespread, but see Liu et al. [12] for a list of facilities for WEEE recycling in China. Specifically on recycling of WEEE, Li et al. [11] state that informal disassembly, as compared to professional disassembly by licensed recycling firms, is still the main method of recycling in China. Xu et al. [22] present a comparison between different modes in recycling management such as self-run, jointly-run and outsourced. Finally, Xin and Wang [21] present an analysis about transnational flows of e-waste (much of it illegally imported), and the related recycling activity in coastal China. They conclude that, despite the illegality and non-adherence to environmental rules, the development of recycling activities has been positive for industrialisation in the coastal areas in China.

Apart from the conceptual mappings that have been presented by authors mentioned above, there is, as far as we know, one single source of empirical work on WEEE in China. This was a survey done in the Chinese city of Xian [1] that collects information on the disposal behaviour of Xian citizens for WEEE. We verified some of its results with other previous work and our own investigation among secondhand market vendors in various central districts in Beijing. There is currently little evidence that the WEEE-recycling systems should be similar across cities in China. However, the similarities in different mapping attempts (see the earlier quoted contributions by [17, 24] and [13]), and other evidence from partial investigations in cities and areas across China such as Hainan, Qingdao, Hangzhou, seem to point in this direction.
We model the WEEE flow system as a Markov chain. Such a system is completely determined by its stages and the transition probabilities from stage to stage. This approach is in line with previous work of Yamada et al. [23] and Matsuno et al. [14], Nakashima et al. [15] and Hu et al. [8] in the areas of product recovery and material re-use. Much of the technicalities on Markov Chains in this paper closely follow Grinstead and Snell [6] unless otherwise stated.

We analyse policy scenarios in the Markov model through the analysis of perturbations of the matrix of transition probabilities. See, for instance, Seneta [16], Cho and Meyer [4] and Hunter [9, 10]. The literature on matrix perturbations in a Markov Chain context provides bounds on, for instance, equilibrium probabilities that allow for the assessment of the impact of certain perturbations on the system as a whole.

\section{Data collection and verification}

The complete WEEE system in China consists of product recovery, re-selling, and recycling activities. Since recycling in China largely takes place in an informal way (see the claim by [11]), there are not enough data to actually investigate recycling in any depth. We therefore concentrate on recovery, re-selling, and disposal.

Especially the existence of extensive re-selling activities of WEEE in China sets the Chinese WEEE system apart from the European system. Waste is valuable in China to a large group of low-income-earning people (mainly present and former migrant workers), and as a result, much of the WEEE in China is re-circulated into the economy and re-used, instead of recycled and broken down into components or raw materials.

As a first step, we gather information on the flow of WEEE from the point in time where users want to get rid of equipment. From observations among collectors, collection points and secondhand markets, the following process emerges: it starts with a consumer. He/she wants to throw something away, and usually passes it along to a street hawker with a tricycle, who pays the consumer a little for the remaining value of the product. This hawker then drives to a collection point (usually a street corner), where a trader takes the goods out of his/her hands, again for a small fee. This trader then drives to a secondhand market, where small shops are run by individual vendors. They buy goods from the traders, and resell them in one way or another. The final buyers are often village people from the country side who cannot afford new equipment, students, or migrant workers whose stay in China's cities is necessarily temporary. Buyers can also represent village 
enterprises who take care of scrapping and recycling. These persons usually buy in bulk the products that the secondhand market vendors cannot sell anymore.

In the Chinese city of Xian, a survey was performed by researchers of Xian Institute of Engineering Science and Technology to identify this process in some more detail. This survey had 550 respondents and was performed in 2004 [1]. The survey was concerned with volume of WEEE, measured in units of products. They distinguished five stages: consumer, collector, secondhand market, dealer and a final stage that could either be a buyer or disposal. The dealer is a retail shop where consumers usually buy their new products. The largest retail chain for electronics in China is called Gomé. The survey reveals that consumers either pass on goods to relatives $(21.5 \%)$, give them to a collector or hawker $(55 \%)$, bring them to a secondhand market $(15.3 \%)$, give products back to the dealer, either as commercial return or because they are broken and fall under warranty $(7.8 \%)$ or dispose of them as waste $(0.4 \%)$.

The collectors then sell the product back to consumers $(1.4 \%)$, bring it to a secondhand market $(72.1 \%)$, bring it back to the original dealer $(2.4 \%)$, dispose of it as waste $(15.9 \%)$ or refurbish it and then sell it to consumers $(8.2 \%)$. At the secondhand market, $1 \%$ of products is directly sold to consumers, and of the remainder, $54.7 \%$ is taken apart, while $44.3 \%$ is sold after refurbishment.

It is not very well known what happens with the $54.7 \%$ that is taken apart. Clearly, this flow is not recycled for the full $100 \%$. In fact, only a small part of it may turn out to be re-used. This concerns, for instance, the valuable metal components in many types of electronic equipment. These make up only a small part of volume or weight of the product volume, but constitute a large part of the value. We will assume that, after taking the product apart, components remain that cannot be re-sold directly to the consumer. We will therefore consider this $54.7 \%$ as disposed of in our model.

Liu et al. [13] present a more recent survey among consumers in Beijing, but this survey does not recognise the secondhand market explicitly. Their survey shows percentages as follows: consumers pass goods on to friends/relatives $26.1 \%$, store them $7.1 \%$, give them to collectors $49.7 \%$, retailers $13.6 \%$ or discard them as waste $3.5 \%$. These percentages are not equal but are fairly similar to the ones from the Xian survey.

The Xian survey is in accordance with our own findings among vendors of secondhand markets in Beijing, which shows that the vendors sell about $50 \%$ of what they collect or buy, and recycle the other $50 \%$ by taking it apart or selling it to recycling purchasers from formal recyclers or from recycling villages.

We have also investigated buyers at secondhand markets $\left(\right.$ see $\left.[18]^{2}\right)$. The distribution across different possibilities for throwing away their secondhand products (sell to collector, give to relatives, dispose as waste) turns out to be more or less the same as for first users. We will therefore consider first and second users as a single group.

\section{Markov chain model}

From the descriptions in the previous section, we identify the following stages in the Markov chain model: (1) consumer, (2) collector (or 'hawker'), (3) secondhand vendor, (4) dealer, (5) refurbishment and (6) disposal. The process is depicted in Fig. 1.

A Markov chain is completely determined by a set of stages $s_{i} \forall i$ and the transition probabilities $p_{i j}=$ $P$ [system is in stage $j$-system was in state $i] \forall i, j$. The transitions occur at fixed points in time. This means that the dwell time in the various stages is not considered in this analysis. With some additional assumptions, we can draw up the matrix of transition probabilities for a WEEE Markov chain in China. We assume that:

1. The system describes the process of throwing away complete electronic products.

2. 'Refurbishment' is a separate state where products are repaired, cleaned and otherwise made suitable for re-use.

3. Intermediate traders are not included as a separate state,

4. The stages 'consumers' and 'relatives' are the same. The probability that consumers pass on goods to relatives is therefore the probability that the goods stay in that stage,

5. The products dealers receive are $50 \%$ broken, which means they get refurbished, and the other half are commercial returns that can be re-sold to other customers.

6. Refurbished products will be sold to customers immediately and completely.

7. Disposal is an absorbing state.

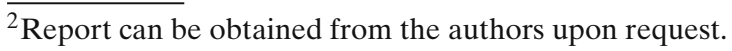




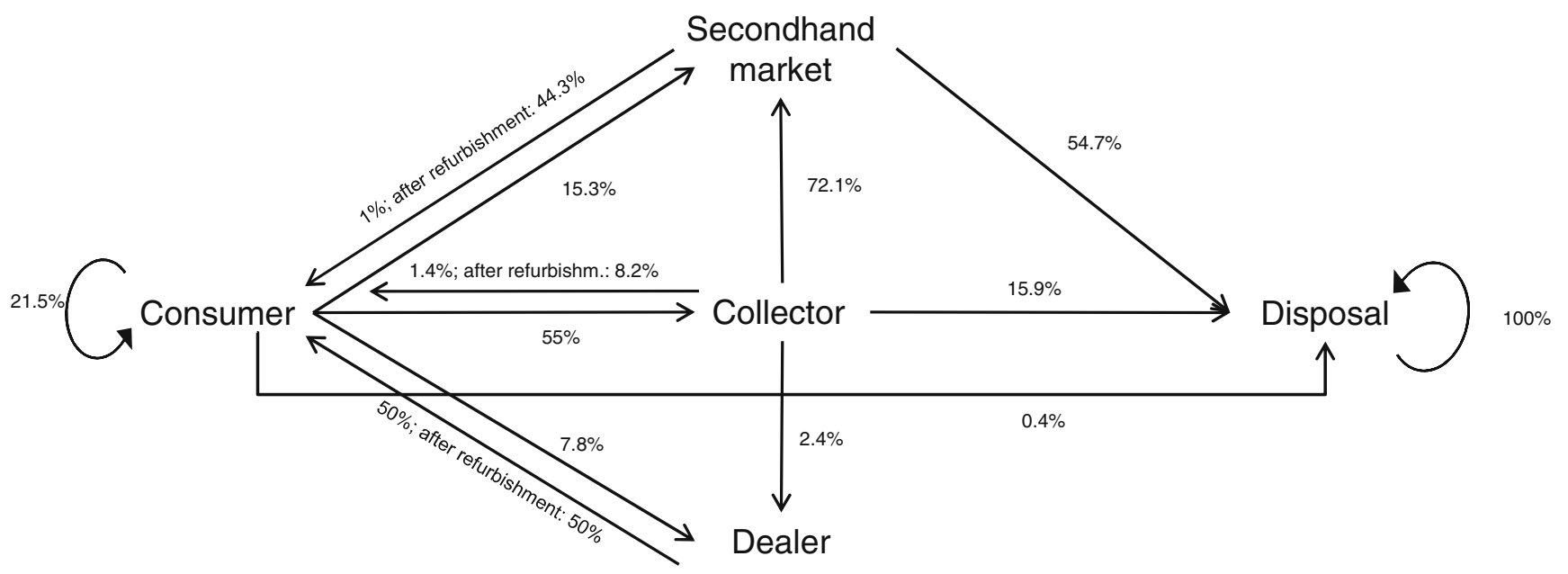

Fig. 1 China WEEE recirculation Markov chain

The matrix of transition probabilities now becomes:

$$
\mathbf{P}=\left(\begin{array}{cccccc}
\text { cons. } & \text { coll. } & \text { vendor } & \text { dealer } & \text { refurb. } & \text { disp. } \\
0.215 & 0.55 & 0.153 & 0.078 & 0 & 0.004 \\
0.014 & 0 & 0.721 & 0.024 & 0.082 & 0.159 \\
0.01 & 0 & 0 & 0 & 0.443 & 0.547 \\
0.5 & 0 & 0 & 0 & 0.5 & 0 \\
1 & 0 & 0 & 0 & 0 & 0 \\
0 & 0 & 0 & 0 & 0 & 1
\end{array}\right)
$$

The matrix Eq. 1 is written in canonical form $\left(\begin{array}{cc}\mathbf{Q} & \mathbf{R} \\ 0 & 1\end{array}\right)$. The matrix $\mathbf{Q}$ is the basis for the assessment of what happens to this Markov chain after $n$ periods. It can be proven that $\mathbf{Q}^{n} \rightarrow 0$ for large $n$. Furthermore, it can be shown that the matrix $\mathbf{I}-\mathbf{Q}$ has an inverse $(\mathbf{N})$. Element $n_{i j}$ of this inverse gives the number of times the system will be in state $s_{j}$, given it starts in state $s_{i}$. The number of states that are passed through until absorption is given by $\mathbf{t}=\mathbf{N c}$, where $\mathbf{c}$ is a unity vector.

A Markov chain does not allow an analysis of time other than counting time steps. However, based on our analysis among secondhand vendors and buyers [18], we can give some indication of the duration of some of the states: $78 \%$ of the secondhand users use a product for 1 or 2 years, a collector has the products usually no longer than a day, $75 \%$ of the vendors sell products within half a year, refurbishment may take 1 or 2 months, after which the product sells relatively quickly. From these figures, one can see that re-selling products in a secondhand market and re-use by secondhand users results in a delay of up to several years of products being disposed of.
We have already noted above that actual recycling in China is limited, and that the WEEE system consists of considerable re-selling and secondhand trading activities. In addition, recycling in China is actually an activity that generates considerable pollution. As such, the effectiveness of the system could be measures in terms of the amount of time (or in our case, the number of steps) it takes between throwing products away and final disposal. If the gap between these two stages increased (because there are more stages in between), we will find that the effectiveness of the system in recirculation products and avoiding disposal increases. We will use the vector $\mathbf{t}$ and diagonal elements of matrix $\mathbf{N}$ as indicators of this effectiveness.

\section{Base case}

The base case represents the situation as it currently is in large cities in China. We report the calculation of the matrix $\mathbf{N}$ and the vectors $\mathbf{t}$. Given that there is one absorbing state, $\mathbf{N}$ is a $5 \times 5$ matrix, representing the transient states, and $\mathbf{t}$ is a $5 \times 1$ vector.

$\mathbf{N}=\left(\begin{array}{llllll}\text { consumer } & 2.6 & 1.4 & 1.4 & 0.2 & 0.9 \\ \text { collector } & 1.1 & 1.6 & 1.3 & 0.1 & 0.8 \\ \text { secondh.vendor } & 1.2 & 0.6 & 1.6 & 0.1 & 0.8 \\ \text { dealer } & 2.6 & 1.4 & 1.4 & 1.2 & 1.4 \\ \text { refurbishm. } & 2.6 & 1.4 & 1.4 & 0.2 & 1.9\end{array}\right)$,

and $\mathbf{t}=\left(\begin{array}{l}6.44 \\ 5.03 \\ 4.36 \\ 7.94 \\ 7.44\end{array}\right)$ 
In $(\mathbf{N})$, the state representing the consumer is the most important: all reverse flows always start at this state. In the base case, the model shows that the products return to this state about two times: $N_{11}=2.6$. In other words, a product has three lives. We will look, among others, at this indicator below to evaluate the outcome of alternative scenarios.

Vector $\mathbf{t}$ indicates that the number of transitions to absorption takes between 4.4 and 7.9 steps, depending on the starting position of the system. These steps do not say much about the actual time it takes for products to end up as waste. However, it does show that products that are with customers, dealers or being refurbished end up in the disposal state after more steps than products that are in the secondhand market or with traders. In the current case, the secondhand market is, in fact, the shortest path to disposal.

Finally, we investigate the stability of the system generated by our matrix $\mathbf{P}$ through the calculation of the eigenvalues. It is well known (theorem of PerronFrobenius) that a stochastic matrix such as ours should have one eigenvalue equal to 1 . As [16] states, if the second largest eigenvalue is also close to 1, the Markov chain is very sensitive to small perturbations of the transition matrix. In our case, the second eigenvalue is 0.83 . We therefore expect a disproportional reaction to small changes in some of the entries of $\mathbf{P}$.

With this model, we can study scenarios on how the Chinese WEEE recirculation system may change. We are interested in changes as a result of the introduction of the new regulation. We will study several cases that reflect likely changes in different parts of the system.

\section{Alternative systems}

The base case model can be changed in many different ways. We make a choice to investigate three scenarios. These scenarios represent ways in which the Chinese government could actually influence and improve the current WEEE system, while at the same time adopts approaches from the way Europe is trying to regulate and control WEEE. We will study the following alternatives:

1. Refurbish and resell a (small) part of the disposed products

2. Increase the selling/disposal ratio at secondhand markets and recovery of products by dealers

3. Increase the role of dealers in direct product recovery; selling direct or through secondhand markets

Other possible scenarios, such as regulating the hawkers, removing or closing down secondhand mar- kets and introducing disposal fees to pay for a centralised collection seem to be less likely in China.

The first case relaxes the assumption that disposal is an absorbing state. Some of the waste that is disposed of by the secondhand market vendors may actually be recirculated because it is refurbished after collection from a waste disposal site, or in a scrapping village that bought up a batch of unsalable products. Note that this is not really recycling, in the sense that raw materials are recovered. Rather, it is re-use of the original product.

There is, however, little information available as to the volume of this type of recirculation and reuse and the environmental impact. The impact of a further refurbishment of disposed products can be studied with the model, although we admit that the potential for this type of refurbishment would be limited. Chinese waste disposal sites are virtual gold mines for all kinds of underprivileged people who collect anything of value, and repair or resell it. While the chance that these people will find electronic equipment that they can still repair and resell is rather small, this chance is increased by the fact that secondhand vendors are not very good at assessing the repairability of the electronic equipment they handle. Another possibility in China could be that a professional repair company 'mines' the disposal sites for any re-usable electronic equipment, and repairs and sells it, possibly through a secondhand market. As a final argument, we also include this case to investigate the inherent system instability that we identified on the basis of the structure of the transition matrix.

We can also study the impact of improving the role of the secondhand markets in terms of their sales-todisposal ratio. Currently, the disposal rate of secondhand markets stands as high as $55 \%$. Improving the selling rate at secondhand markets could be done by offering the secondhand vendors (often former migrant workers that got laid off at a construction site) a professional education program on electronics repair and refurbishment or to improve technical supervision at secondhand markets to avoid disposal of repairable products.

Finally, in light of the development of Chinese regulation as a mirror image of the European regulation, we study the impact of increasing the role of the dealers in recovering products to reflect a greater focus on producer responsibility. In many countries in Europe, the dealers and retailers who sell new electrical and electronic equipment play an important role in taking back old and used equipment. The selling price of the new equipment usually includes a fee that pays for the return logistics. In China, returning goods through dealers is not very common, and the only returns the 
dealers receive are commercial returns of goods broken or rejected within the warrantee period. Dealers might recover their products in various ways. We will study two possibilities: direct recovery and recovery via secondhand markets. We also look into two alternative channels for re-selling: direct selling to customers and re-selling via secondhand markets.

We will analyse the impact of these scenarios by means of the Markov model, and we will provide a further qualitative analysis of the sustainability of the Chinese WEEE system by assessing the impact on the three Ps: people, planet and profit. We compare the outcome of the various scenarios against the benchmark of the base case, according to the following principles:

- Delaying the time to disposal is positive for people and planet and neutral for profit: more people can buy cheap secondhand products, pollution as a result of disposal is delayed.

- Reducing the role of secondhand markets is negative for people due to the loss of jobs in secondhand markets.

- Reducing the volume of disposed products is positive for planet.

- Increasing the role of dealers is negative for profit (in China, dealers have to buy the products back from the consumers).

- Increasing the role of refurbishment is positive for people and profit: it will provide better products to people, and require higher skills, it will generate more profit from selling the products.

In the first scenario, the system will no longer be absorbing. In fact, the system is now ergodic. For such a system, the equilibrium probabilities reflect what part of the time the system is in what state.

A possibility to analyse ergodic Markov chains is to calculate a 'fundamental' matrix, in the same way as for absorbing Markov chains, as follows:

$\mathbf{Z}=(\mathbf{I}-\mathbf{P}+\mathbf{W})^{-1}$,

where $\mathbf{I}$ is the identity matrix, $\mathbf{P}$ the transition matrix and $\mathbf{W}$ the matrix with equilibrium probability vector $w$ as its rows $(w$ satisfies $w \mathbf{P}=w)$. It can be proven that $\mathbf{Z}$ exists (see [6]), and satisfies $w \mathbf{Z}=w$. From the elements of $\mathbf{Z}$, the elements of the mean first passage time matrix $\mathbf{M}$ can be calculated:

$m_{i j}=\frac{z_{j j}-z_{i j}}{w_{j}}$.

The element $m_{i j}$ indicates the time the system reaches state $j$ after a start in state $i$ for all $i \neq j$. Finally, the mean recurrence matrix $\mathbf{D}$ has, on the diagonal, the mean recurrence times, which are the inverse of the equilibrium probabilities: $d_{i i}=r_{i}=1 / w_{i}$.

The way to study the cases listed above is by analysing the impact of a perturbation of the transition matrix on the characterisation of the system through the vector $\mathbf{t}$ and matrix $\mathbf{N}$ in the absorbing cases and the equilibrium probabilities $\mathbf{w}$ and related matrices in the ergodic cases. Some authors have developed sensitivity measures and bounds for perturbation of transition probabilities. Hunter [9] develops a statistic $v_{i}=\sum_{j=1}^{s} m_{i j} w_{j}$, where $s$ is the number of states, and that has a lower bound for an $s$-state Markov chain of $v=s$. If $v$ is large, the system is sensitive for small perturbations. Hunter [10] presents another way of analysing sensitivity to perturbation through the socalled 'mixing matrix' $=\left[x_{i j}\right]=\left(1-\delta_{i j}\right) m_{i j} w_{j}$. From this matrix, the maximum absolute and relative differences in the equilibrium probabilities can be calculated for all possible perturbations in matrix $\mathbf{P}$. Cho and Meyer [4] provide bounds for the absolute and relative changes of the equilibrium probabilities as follows:

$\left|w_{j}^{(1)}-w_{j}^{(2)}\right| \leq \frac{\|E\|_{\infty}}{2} \frac{\max _{i \neq j}\left\{m_{i j}^{(1)}\right\}}{m_{j j}^{(1)}}$,

and $\left|\frac{w_{j}^{(1)}-w_{j}^{(2)}}{w_{j}^{(1)}}\right| \leq \frac{\|E\|_{\infty}}{2} \max _{i \neq j}\left\{m_{i j}^{(1)}\right\}$,

where $\|\cdot\|_{\infty}$ is the maximum row sum norm and $\mathbf{E}$ the perturbation matrix $\left(\mathbf{E}=\mathbf{P}^{(2)}-\mathbf{P}^{(1)}\right)$. The values of these bounds are an indication of which variable is the most sensitive to the perturbation.

\subsection{Case 1: impact of refurbishing a small part of disposed products}

For this case, we change two elements in matrix $\mathbf{P}$ that correspond with the waste state as follows: $p_{65}=\overline{\mathrm{p}}$ and $p_{66}=1-\overline{\mathrm{p}}$, with $0<\overline{\mathrm{p}}<<1$. This reflects a positive probability that a small portion of disposed products is picked up from a waste disposal site, and refurbished after all. An analysis of the mixing matrix for the case of $p_{65}=0.05$ reveals that the maximum possible change in equilibrium probabilities is the largest for possible perturbations involving the sixth state (disposal). The detailed results are not reported here due to lack of space. We report results for various values of $\bar{p}$ in Table 2.

The results show that the equilibrium distribution is quite unstable for low values of $\bar{p}$, for perturbations involving the disposal state, as we expected. From the eigenvalues, however, we can see that this instability 
Table 2 Equilibrium probabilities for various values of $\overline{\mathrm{p}}$; (values in \%)

\begin{tabular}{lccc}
\hline State & $\overline{\mathrm{p}}=0.01$ & $\overline{\mathrm{p}}=0.05$ & $\overline{\mathrm{p}}=0.10$ \\
\hline Consumer & 2.6 & 10.6 & 16.0 \\
Collector & 1.5 & 5.8 & 8.8 \\
Secondh. market & 1.5 & 5.8 & 8.8 \\
Dealer & 0.2 & 1.0 & 1.5 \\
Refurbishment & 1.9 & 7.7 & 11.6 \\
Waste & 92.3 & 69.1 & 53.2 \\
$r_{6}$ & 1.08 & 1.45 & 1.88 \\
$2^{\text {nd }}$ ev & 0.82 & 0.80 & 0.74 \\
\hline
\end{tabular}

The equilibrium probabilities are approximated by taking a row from $P^{20}$. In this matrix, the difference between values in a column does not exceed 0.0001. $r_{6}$ is the mean return time to the waste state, condition on a start in the waste state. $2^{\text {nd }} \mathrm{ev}$ stands for second eigenvalue; this refers to the matrix of transition probabilities after perturbation

diminishes if we increase $\bar{p}$. The instability is confirmed by the Hunter's $v$ statistic, which is equal to 8 , while the lower bound for a system with six states is 6 . We also find that the upper bounds according to Eq. 6 are especially high for the waste state, but become gradually lower for higher values of $\bar{p}$.

We conclude from this that decreasing disposal through 'last-minute refurbishment' by even a small amount will have a great impact on the disposal volume in the equilibrium state. This shows that there might be some real potential of reducing the waste flow as a result of 'mining' disposal sites or filtering the disposal from secondhand markets.

\subsection{Case 2: increasing the selling/disposal ratio} in secondhand market

To investigate the functioning of the secondhand market, we start from the base case, and adjust probabilities $p_{35}$ and $p_{36}$, in such a way that more products are sold, and less thrown away (note that $p_{35}=1-0.01-p_{36}$ ). We also study the case that all unsold products at secondhand markets are not disposed of, but taken back by the dealers. This means we set $p_{36}=0$ and $p_{34}=0.547$.

The impact of selling more and throwing less away at the secondhand market is less spectacular than the previous case of increasing waste recycling. The $(1,1)$ element of $\mathbf{N}$ increases steadily, from 2.6 to 5.0. This shows that steadily decreasing disposal at the secondhand market is effective in postponing disposal.

A more powerful impact is achieved by including the dealers in the scenario (most righthand-side column of Table 3). If the dealers buy up the residual products at the secondhand markets, the number of steps to disposal is increased substantially. This seems to lend support to the concept of producer responsibility because it shows that including the producers or their retailers and dealers in the recovery process can be quite effective in reducing disposal. Note that, due to the nature of our model, we have to assume these dealers refurbish and re-sell the products, instead of recycling them. In the Chinese context, however, this is not an unrealistic assumption at all.

\subsection{Case 3: impact of the extended role of dealers}

We investigate the direct recovery by dealers by changing probability $p_{14}$. We assume that, by returning more through dealers, less of the goods will be collected by collectors or hawkers in the street. Therefore, the increase in $p_{14}$ will result in a corresponding reduction of $p_{12}$. We will assume the dealers will refurbish about $90 \%$ of the products they receive and sell them to consumers $\left(p_{45}=0.9, p_{41}=0.1\right)$. We consider two subcases: dealers sell to consumers directly (as in the base case) ( $\left.p_{51}=1, p_{36}=0.547\right)$ or they sell to consumers through the secondhand markets $\left(p_{53}=1\right)$. The latter scenario means that they provide the secondhand market vendors with refurbished products. To reflect this, we also change the disposal rate of the secondhand market: $p_{36}=0.3$ instead of 0.547 (adjusting $p_{35}$ accordingly) (Table 4).

From the table, we see that the values for $\mathbf{t}$ for the various stages, as well as the value for $N_{11}$, are gradually increasing for the sub-scenario where dealers take back gradually more products, repair and refurbish and sell them back directly to customers. This again lends support for the potential positive impact
Table 3 t vector (time to absorption) and $N_{11}$ for various values of $p_{35}$ and $p_{36}$

\begin{tabular}{lllrll}
\hline State & $p_{36}=0.547$ & $p_{36}=0.4$ & $p_{36}=0.3$ & $p_{36}=0.2$ & $\begin{array}{l}p_{36}=0 \\
p_{34}=0.547\end{array}$ \\
& & & & & 32.54 \\
Consumer & 6.44 & 8.37 & 10.38 & 13.49 & 30.12 \\
Trader & 5.03 & 6.89 & 8.82 & 11.81 & 34.80 \\
Secondhand market & 4.36 & 6.61 & 8.96 & 12.58 & 34.04 \\
Dealer & 7.94 & 9.87 & 11.88 & 14.99 & 33.54 \\
Refurbishment & 7.44 & 9.37 & 11.38 & 14.49 & \\
& & & & & \\
$N_{11}$ & 2.6 & 3.2 & 3.9 & 5.0 & 10.9 \\
\hline
\end{tabular}


Table $4 \mathbf{t}$ vector (time to absorption) for various values of $p_{14}$

\begin{tabular}{|c|c|c|c|c|c|c|}
\hline \multirow[t]{2}{*}{ State } & \multicolumn{3}{|c|}{$\begin{array}{l}\text { Sell to consumer } \\
\underline{p_{41}=1, p_{36}=0.547}\end{array}$} & \multicolumn{3}{|c|}{$\begin{array}{l}\text { Sell to secondhand market } \\
p_{43}=1, p_{36}=0.3\end{array}$} \\
\hline & $p_{14}=0.078$ & $p_{14}=0.2$ & $p_{14}=0.4$ & $p_{14}=0.078$ & $p_{14}=0.2$ & $p_{14}=0.4$ \\
\hline Consumer & 6.53 & 7.79 & 11.57 & 7.31 & 7.61 & 8.12 \\
\hline Trader & 5.09 & 5.64 & 7.34 & 5.94 & 5.95 & 5.97 \\
\hline Secondhand market & 4.40 & 4.97 & 6.69 & 5.69 & 5.70 & 5.91 \\
\hline Dealer & 8.43 & 9.69 & 13.47 & 7.75 & 7.79 & 7.85 \\
\hline Refurbishment & 7.53 & 8.79 & 12.57 & 6.69 & 6.70 & 6.71 \\
\hline$N_{11}$ & 2.6 & 3.1 & 4.7 & 1.3 & 1.4 & 1.4 \\
\hline
\end{tabular}

of increasing producer responsibility through retailers and dealers. If, however, these dealers sell back the products through secondhand markets, the increases in $N_{11}$ are almost negligible. Note also that, in this case, the $N_{11}$ indicator shows much more clearly than the elements of $\mathbf{t}$ that this scenario performs much worse than the base case. Without further improvement of the functioning of the secondhand markets, a take-back policy that relies on reselling via secondhand markets may not be so successful. Retailers and dealers should thus be stimulated to corner off part of their stores for selling secondhand goods directly to consumers, or otherwise keep secondhand sales under direct control.

\subsection{Evaluation of people, planet and profit}

Based on the criteria in the beginning of Section 6, we can perform a qualitative evaluation of the various scenarios. The outcome of this evaluation is reported in Table 5.

For case 1, the outcome are the result of the increase of time to disposal, combined with the impact of reducing the volume of disposal. In cases $2 \mathrm{a}$ and $2 \mathrm{~b}$, an increase of the time to disposal leads to a positive outcome, but the effect in case $2 b$ is more pronounced than in case $2 \mathrm{a}$. For $3 \mathrm{a}$ and $3 \mathrm{~b}$, there is a more or less neutral impact on profit, due to the combined effect of increasing the role of dealers $(-)$, and increasing refurbishment $(+)$. In case $3 \mathrm{a}$, the effects of people and planet are due to the increased time to disposal. This effect is not present in case $3 b$, but there is a positive effect on people, due to the increased use of

Table 5 Evaluation of people, planet and profit

\begin{tabular}{llll}
\hline Case & People & Planet & Profit \\
\hline Base case & Benchmark & & \\
1 & + & ++ & \\
$2 \mathrm{a}$ & + & + & \\
$2 \mathrm{~b}$ & ++ & ++ & \\
$3 \mathrm{a}$ & + & + & $+1-$ \\
$3 \mathrm{~b}$ & + & & $+/-$ \\
\hline
\end{tabular}

secondhand markets. In conclusion, the new policy in China is probably not going to generate much profit for parties involved, but there will be positive effects on people and planet. The magnitude of these effects depends on the specific scenario.

\section{Concluding remarks}

In this paper, we analyze WEEE product flows in China through a Markov chain model. We study a base case, and three alternative models, that reflect last-minute refurbishment of disposed goods, improving the performance of secondhand markets, and increasing the role of dealers and retailers in product recovery. Especially this last scenario reflects the changes one might expect in the Chinese system of WEEE recycling as a result of adopting the concept of EPR.

The current study has some important limitations: we have assumed that our Xian data source reflects developments in other cities. This could be investigated further by repeating a similar survey in other cities. We have also not included the dwell times in the various stages into the analysis. These dwell or sojourn times would allow a quantitative assessment of the postponement effect of better reselling and refurbishment compared to our qualitative analysis.

Our findings reveal that the Markov chain is especially sensitive to perturbations related in the lastminute refurbishment scenario. Even small amounts of disposed goods that are withdrawn from this state reduce the equilibrium probability of the disposal state considerably. The scenario of improving the role of secondhand markets shows that reducing the disposal from secondhand markets, but more particularly letting dealers buy up disposed products in secondhand markets, has a large impact on the number of steps goods go through to end up in the disposal state. Finally, the increased role of dealers is shown to have an impact on extending the recirculation of products, and this is more effective if the dealers sell the refurbished products 
to consumers themselves than when they rely on secondhand markets to do this. The qualitative evaluation of the impact on the three Ps also confirms that the cases where EPR is introduced, by means of dealers recovering products through the secondhand markets, can be expected to have a positive impact on people and planet. The impact on profit is neutral, depending on the balance between profit from refurbishment and cost of recovery.

On the basis of this analysis, we gained new insights about WEEE recirculation in China. If China chooses to follow the European approach of EPR, it would have to get the dealers and retailers more actively involved in recovery. Both recovery directly from consumers and recovery through the secondhand markets can be very effective in reducing disposal of products. This means that, even in case the EPR is introduced in China, the current collection system can continue to exist as an effective logistic channel for the recovery of products. The analysis also shows the secondhand markets are weak sales channels, with a high degree of disposal. In their current state, secondhand markets will not be acceptable as re-selling channels for producers, dealers and retailers. If this is to change, the Chinese government would have to develop a technical assistance program for the secondhand market vendors to improve their performance. Finally, we show that sorting the volume of disposed products and filtering out anything that is still of use can be an effective way to reduce waste volumes. Due to the system instability, only a limited effort may already have considerable impact on waste volumes. In summary, we can conclude that the WEEE regulation that is introduced in China, with EPR as a central concept, can work in the context of the Chinese WEEE recovery and recirculation system, as long as dealers and retailed keep the re-selling activity in their own hands.

In a further study, we aim to extend this analysis by explicitly modelling sojourn times in various states through semi-Markov models. This would allow a more accurate measurement of time to disposal, and of the increase in time to disposal as a result of the scenarios analysed above.

Open Access This article is distributed under the terms of the Creative Commons Attribution Noncommercial License which permits any noncommercial use, distribution, and reproduction in any medium, provided the original author(s) and source are credited.

\section{References}

1. Anonymous (2005) Xian weee flow survey (in Chinese). www.xawb.com

2. Anonymous (2007) China's e-waste nightmare worsening. peoplepc, www.peoplepc.com, 18 November 2007

3. Cao M, Xu H (2006) Research on recycling of weee. Technology Administration Research (8):60-63

4. Cho G, Meyer C (2001) Comparison of perturbation bounds for a stationary distribution of a Markov chain. Linear Algebra Appl 335:137-150

5. EU-EC (2003) Directive 2002/95/ec of the european parliament and of the council of 27 January 2003 on the restriction of the use of certain hazardous substances in electrical and electronic equipment. European Legal Journal, 27 January 2003

6. Grinstead C, Snell J (1997) Introduction to probability. American Mathematical Society, Providence

7. He W, Li G, Ma X, Wang H, Huang J, Xu M, Huang C (2006) Weee recovery strategies and the weee treatment status in China. J Hazard Mater B136:502-512

8. Hu G, Wang L, Bidanda B, Wang Y (2007) A new model for closed-loop product lifecycle systems. In: Bayraksan G, Lin W, Son Y, Wysk R (eds) 2007 industrial engineering research conference

9. Hunter J (2003) Mixing times and applications to perturbed Markov chains. Res Lett Inf Math Sci 4:35-49

10. Hunter J (2006) Perturbing Markov chains. Tech. Rep., unpublished manuscript; Massey University, New Zealand

11. Li J, Wen X, Liu T, Honda S (2005) Policies, management, technologies and facilities for the treatment of electrical and electronic wastes in China. Tech. Rep., Basel Convention Regional Center

12. Liu X, Tanaka M, Matsui Y (2006) Electrical and electronic waste management in China: progress and the barriers to overcome. Waste Manag Res 24:92-101

13. Liu X, Tanaka M, Matsui Y (2006) Generation amount prediction and material flow analysis of electronic waste: a case study in Beijing, China. Waste Manag Res 24:434-445

14. Matsuno Y, Daigo I, Adachi Y (2007) Application of Markov chain model to calculate the average number of times in use of a material in society-part 2. Int J Life Cycle Assess 12(1):34-39

15. Nakashima K, Arimitsu H, Nose T, Kuriyama S (2002) Analysis of a product recovery system. Int J Prod Res 40(15): 3849-3856

16. Seneta E (1991) Numerical solutions of Markov chains, Marcel Dekker Inc, New York, chap sensitivity analysis, ergoicity coefficients and rank-one updates for finite Markov chains, pp 121-129

17. Streicher-Porte M, Yang J (2007) Weee recycling in China. Present situation and main obstacles for improvement. In: Proceedings of the 2007 IEEE international symposium on electronics \& the environment, pp 40-45

18. Veenstra A, Wang Y, Fan W, Ru Y (2009) The role of secondhand markets in weee recycling in China. Tech. Rep., Rotterdam School of Management/Beijing Jiaotong University

19. Wei J, Li J, Wei H (2005) Research on recycling model of e-waste. Logist Technol 10(1):28-30

20. Xie F, Hu T (2005) Preventing weee pollution by promoting recycling. In: Environment protection in railways 
21. Xin T, Wang J (2004) Transnational flows of e-waste and spatial patterns of recycling in China. Eurasian Geography and Economics 45

22. Xu J, Zhang Y, Jin Y (2006) Selection of weee recycling modes. Environ Forum 3:76-79

23. Yamada H, Daigo I, Matsuno Y, Adachi Y, Kondo Y (2006) Application of Markov chain model to calculate the average number of times in use of a material in society-part 1. Int $\mathrm{J}$ Life Cycle Assess 11(5):354-360

24. Yang J, Lu B, Xu C (2007) WEEE flow and mitigating measures in China. Waste Management 28:15891597

25. Zhou C, Xu C (2005) Research on system planning model of weee recycling. Forecasting 24(6):74-78 